\title{
Overdose-Associated Admissions Among People Who Inject Opioids at a County Safety-Net Hospital Following Implementation of a Syringe Services Program
}

Kasha Bornstein ( $\nabla$ kashabornstein@gmail.com )

https://orcid.org/0000-0002-1779-9184

\section{Austin Coye}

University of Miami School of Medicine https://orcid.org/0000-0003-2169-2539

Joan St. Onge

University of Miami Health System

Hua Li

University of Miami

Amanda Muller

Florida Department of Children and Families

Tyler Bartholomew

University of Miami

Hansel Tookes

University of Miami Health System

\section{Brief report}

Keywords: Syringe Services Program, Take-Home Naloxone, overdose, opioid epidemic

Posted Date: February 28th, 2020

DOI: https://doi.org/10.21203/rs.2.24784/v1

License: (9) (i) This work is licensed under a Creative Commons Attribution 4.0 International License. Read Full License

Version of Record: A version of this preprint was published at Harm Reduction Journal on May 12th, 2020. See the published version at https://doi.org/10.1186/s12954-020-00376-1. 


\section{Abstract}

\section{Background}

Syringe service programs (SSPs) are an evidence-based harm reduction strategy that reduce dangerous sequelae of injection drug use among people who inject drugs (PWID) such as overdose. SSP services include safer injection education and community-based naloxone distribution programs. This study evaluates differences in overdose-associated hospital admissions following implementation of the first legal SSP in Florida, based in Miami-Dade County.

\section{Methods}

We performed a retrospective analysis of hospitalizations for injection drug-related sequelae at a county hospital before and after the implementation of the SSP. An algorithm utilizing ICD-10 codes for opioid use and sequelae was used to identify people who inject opioids (PWIO). Florida Department of Law Enforcement Medical Examiners Commission Report data was used to analyze concurrent overdose death trends in Florida counties.

Results

Over the 25-month study period, 302 PWIO admissions were identified; 146 in the pre-index vs. 156 in post-index. A total of 26 admissions with PWIO overdose were found; 20 pre-index and 6 post-index $(p=0.0034)$.

Conclusions

Declining overdose-associated admissions among PWIO suggests early impacts following SSP implementation.

\section{Introduction:}

In 2017, the Centers for Disease Control and Prevention announced drug overdose mortality hit a record high, with 70,237 Americans dying from overdose.(1) The impact of the contemporary overdose crisis is felt heavily in Florida: Opioid-related deaths increased 35\% between 2015 and 2016 statewide(2). More specifically, heroin-associated deaths in Miami-Dade County rose 826\% between 2011-2016(2). With Miami-Dade County atop the list in new HIV infections in the country, implementation of evidence-based HIV prevention coupled with overdose prevention was imperative.(3)

In 2016, Florida enacted the Infectious Disease Elimination Act, allowing a single pilot syringe services program (SSP) in Florida; the University of Miami IDEA SSP (IDEA). In the year following establishment of IDEA in Miami, approximately 518 PWID enrolled in services, and 795 kits of two 4 mg dose naloxone were distributed to participants. In addition to sterile needles and other injection supplies, participants in the IDEA-SSP are provided with education on safe injection practices. They are also instructed in the use 
of tester shots (sampling small amounts of a newly acquired drug before using the entire dose), using drugs with trusted friends, and spreading awareness of locations of previous overdose and bad batchesbatches with unusually potent or otherwise toxic effects.(4)

In addition to exchanging syringes, SSPs provide comprehensive harm reduction services to people who inject drugs (PWID). These services include community distribution of take-home naloxone kits.(5) Takehome naloxone is an effective strategy for mitigating poor overdose outcomes as it reduces the time to administration versus activation of emergency medical services.(6) Community naloxone distribution removes barriers to naloxone access, a critical feature for populations that experience significant hesitation when seeking medical care, partially due to uninsured status, systemic bias and stigma associated with drug use. PWID are commonly the first responders at the scene of an overdose and reverse an overwhelming majority of overdoses in the community. A 2014 survey conducted by the Harm Reduction Coalition showed that from 1996-2014, 136 organizations across the United States distributed over 152,000 naloxone kits to laypersons in the community, and over 26,400 overdose reversals were reported.(7) Of the overdose reversals reported, $82.8 \%$ of individuals that used naloxone to save a life were PWID. Other research shows that PWID deploy take-home naloxone to save a life at a rate nearly ten times that of laypeople who do not use drugs - emphasizing the need to prioritize people who use drugs in naloxone distribution efforts.(8) However, PWID continue to face barriers to naloxone access, including cost and stigma.

Multiple systematic reviews have found take-home naloxone programs to be both safe and effective, leading to increased survival rates among participants and decreases in overdose mortality rates more broadly.(9-11) Although systemic analyses have found take-home naloxone programs are effective in reducing overdose deaths among program participants, there are few studies that assess the impact of take-home naloxone programs on hospitalizations. (10) One study of a community take-home naloxone distribution program that operates independent of an SSP found no reduction in emergency department visits or deaths(12). We present a study analyzing the early effects of the IDEA-SSP on incidence of admissions associated with opioid overdose at a county safety-net hospital in south Florida.

\section{Methods:}

We conducted a retrospective review of hospitalized patients' data at Jackson Memorial Hospital (JMH), a county hospital in Miami, Florida during a 25-month period, from December 1, 2015 to January 1, 2018. Data were separated into two periods, with December 1, 2016-the establishment of the IDEA-SSP-as an index date. To increase specificity of the query, data from December 1, 2016 to January 1, 2017 was excluded, allowing lag time for syringe service implementation. An algorithm used by Tookes et al. (2015) was adapted using International Classification of Diseases, Tenth Revision (ICD-10) codes to query the JMH electronic discharge and billing records for patients aged 18-85 (See Supplemental Table 1).(13) A combination of ICD-10 codes for opioid use and injection-related infections (IRI) were used to identify people who inject opioids (PWIO). Opioid codes included ICD-10 diagnoses related to opioids (See 
Supplemental Table 2). IRI included endocarditis, bacteremia/sepsis, osteomyelitis, abscesses and/or cellulitis diagnoses.

Medical records were abstracted for demographic information, length of stay (LOS), insurance status, and discharge status.

Additionally, we independently analyzed publicly available Florida Department of Law Enforcement Medical Examiner Commission reports from 2012-2017 to identify state and regional trends in opioidrelated mortality to compare to our local findings. (Fig. 1)

\section{Analysis}

Descriptive statistics and frequency distributions for demographics, insurance status, and hospital use variables were utilized. Hospital use variables included discharge status and LOS for each hospitalization. Categorical data were described with numbers and percentages. Comparisons between pre- and post-index in frequencies of clinical and social demographic characteristics were analyzed by Chi-square or Fisher's exact test. Because some continuous variables, such as age and LOS, were not normally distributed, the Wilcoxon Rank-Sum test was used for the comparisons. The results were reported as median and interquartile range. All analyses were performed in SAS 9.4 (SAS Institute Inc., Cary, NC).

\section{Results:}

\section{Demographics}

Of 1360 opioid-related admissions to JMH over the 25-month study period, $302 \mathrm{PWIO}$ admissions were identified; 146 in the pre-index vs. 156 in post-index (Table 1). Race, sex, age and insurance did not differ across pre- and post-index cohorts. Only $3 \%$ of PWIO had private insurance across the two-year timespan. Approximately $60 \%$ of PWIO were uninsured, with no significant difference between cohorts $(p=0.88)$. Hospital mortality rates were not significantly different between the pre and post-index cohorts. Nine (3\%) patients died during the hospital stay as determined by an "expired" discharge status; five pre-index vs. four post-index $(p=0.74)$.

\section{Overdose Sequela}

Overdose-associated admissions significantly declined in the post-index cohort vs the pre-index cohort. In the pre-index cohort, $14 \%$ of admissions involved an overdose diagnosis, vs. $4 \%$ in the post-index cohort $(p=0.0034)$.

\section{Florida Opioid Caused Deaths}

State medical examiner findings demonstrated overall increasing opioid-related deaths in Florida between 2010-2017. From 2014-2016 opioid-caused deaths increased. The rate of increase declined from 2016- 
2017 except in Pinellas and Miami-Dade counties, where opioid related mortality decreased. 
Table 1

PWIO Demographics

\begin{tabular}{|c|c|c|c|}
\hline & $\begin{array}{l}\text { Pre-Index } \\
n=146 \#(\%)\end{array}$ & $\begin{array}{l}\text { Post-Index } \\
n=156 \text { \#, (\%) }\end{array}$ & P-value \\
\hline Biological Sex & & & 0.46 \\
\hline Male & $103(70.6)$ & $103(66.0)$ & \\
\hline Female & $43(29.5)$ & $53(34.0)$ & \\
\hline Race & & & 0.64 \\
\hline White & $118(80.8)$ & $124(79.5)$ & \\
\hline Black & $27(18.5)$ & $29(18.6)$ & \\
\hline Other & $1(0.30)$ & $3(1.9)$ & \\
\hline \multicolumn{4}{|l|}{ Ethnicity } \\
\hline Hispanic & $65(44.5)$ & $57(36.5)$ & 0.16 \\
\hline Non-Hispanic & $81(55.5)$ & $99(63.5)$ & \\
\hline Age in Years & & & 0.17 \\
\hline $16-29$ & $22(15.1)$ & $30(19.2)$ & \\
\hline $30-39$ & $47(32.2)$ & $47(30.1)$ & \\
\hline $40-49$ & $36(24.7)$ & $48(30.8)$ & \\
\hline $50-59$ & $30(20.6)$ & $20(12.8)$ & \\
\hline $60-65$ & $9(6.2)$ & $5(3.2)$ & \\
\hline $65-85$ & $2(1.4)$ & $6(3.9)$ & \\
\hline Insurance Status & & & 0.90 \\
\hline Uninsured & $85(58.2)$ & $95(60.9)$ & \\
\hline Medicaid & $31(21.2)$ & $34(21.8)$ & \\
\hline Medicare + Federal & $24(16.4)$ & $21(13.5)$ & \\
\hline Private & $5(3.4)$ & $4(2.6)$ & \\
\hline Other & $1(0.7)$ & $2(1.3)$ & \\
\hline $\begin{array}{l}\text { Median } \\
\text { Length of Stay }\end{array}$ & 4 & 2 & 0.14 \\
\hline Expired During Study Period & $5(3.4)$ & $4(2.6)$ & 0.74 \\
\hline
\end{tabular}




\begin{tabular}{|llll|}
\hline & $\begin{array}{l}\text { Pre-Index } \\
n=146 \#(\%)\end{array}$ & $\begin{array}{l}\text { Post-Index } \\
n=156 ~ \#, ~(\%)\end{array}$ & P-value \\
\hline PWIO overdose- associated admissions & $20(13.7)$ & $6(3.9)$ & 0.0034 \\
\hline
\end{tabular}

\section{Discussion:}

Opioid-caused deaths surged in Florida 2010-2017 following national trends in the contemporary opioid overdose crisis. These data explore the unique situation in south Florida after the implementation of the IDEA-SSP. Opioid-caused deaths increased after the 2012 closure of the pill mills and the transition to counterfeit pills and heroin.(14) With the introduction of fentanyl and high-potency synthetic analogues into the drug supply, sharp increases in opioid mortality were seen statewide between 2014-2016. $(2,15)$ Given the unmitigated statewide overdose crisis, it would be expected that hospital data would reflect this trend of increasing overdose-associated admissions. However, following SSP implementation, while number of PWIO in our cohort did not change, overdoses reported in PWIO decreased significantly. The temporal association suggests that the IDEA-SSP community distribution of take-home naloxone may have produced early effects in mitigating overdose-associated morbidity and mortality.

Several statewide opioid epidemic interventions were implemented before and directly following the study period, including a concerted law enforcement effort to close "pill mills", the mandated use of prescription drug monitoring programs and restricted opioid prescribing.(15) However, these statewide policies do not temporally explain Miami-Dade's decline in overdose deaths as reported by the Florida Department of Law Enforcement Medical Examiners Commission (Fig. 1). During the study period of December 2016January 2018, the IDEA-SSP distributed $7954 \mathrm{mg}$ two dose naloxone kits to participants and 387 reversals were reported. Opioid-caused deaths in Miami-Dade County declined from 321 deaths in 2016 to 305 in 2017, representing a 5\% reduction. Similar declines in opioid related mortality were not seen in neighboring counties. Taken together, the hospital data and the medical examiner data suggest early impacts of the first legal SSP in the state, operating in Miami-Dade County. More low-barrier SSPs are needed across Florida to significantly increase naloxone access among PWUD and potentially reduce opioid overdose morbidity and mortality statewide. Due to negative encounters PWID have experienced when receiving services in traditional health care settings, they may be less likely to visit these settings to access naloxone kits - highlighting the importance of establishing naloxone distribution programs in lowbarrier settings where PWID may feel more comfortable, namely SSPs and other harm reduction modalities. Recent modeling simulating the impact of 13 different naloxone distribution modalities on overdose deaths estimated expanding naloxone distribution through a single SSP can reduce a community's overdose deaths by $65 \%$.(16)

Some limitations to this study exist. The ICD-10 does not have specific diagnosis codes for injection drug use or sequelae thereof. As such, this study relied on a novel ICD-10 adaptation of an algorithm using ICD-9 codes for drug use and infectious consequences.(13) Additionally, stigma associated with injection drug use remains widespread, and patients may not have reported use, resulting in under-documentation. 
Most importantly, our data do not imply a causality between the establishment of the SSP and the decrease in opioid-associated admissions. Previous epidemiologic evaluations of SSPs describe a lag time between community SSP implementation and decline in chronic infections such as HIV and HCV. (17) An analysis of HIV rates among PWID in Baltimore only began to show significant decreases after five years of steadily increasing SSP service coverage, remaining in sustained decline thereafter.(17) Future research should be directed towards exploring longer-term effects of the IDEA-SSP. However, taken with the medical examiner data, this study provides important information related to trends of decreasing opioid overdose morbidity and mortality in Miami-Dade County.

Despite these limitations, this study reveals a significant decrease in overdose-associated admissions among PWIO at a county safety-net hospital following the implementation of the IDEA-SSP in the setting of the contemporary Florida overdose crisis. SSPs and take-home naloxone could impact the number of overdose-associated hospital admissions and warrant further study.

\section{Abbreviations}

IDEA-SSP

University of Miami IDEA Syringe Services Program

PWID

People Who Inject Drugs

$\mathrm{JMH}$

Jackson Memorial Hospital

ICD-10

International Classification of Diseases, Tenth Revision

IRI

Injection Related Infections

PWIO

People Who Inject Opioids

LOS

Length of Stay

\section{Declarations}

Ethics approval and consent to participate: The study was approved by the University of Miami Institutional Review Board (IRB \#20180242) and the Jackson Health System Clinical Research Review Committee. Informed consent was not obtained from participants and a consent waiver was granted. Data were de-identified prior to analysis.

Consent for publication: Not Applicable 
Availability of data and materials: The de-identified dataset is available as Supplementary Table 1. Florida Department of Law Enforcement Medical Examiners Commission Reports are publicly available data.

\section{Competing interests: None.}

Funding: We are extremely grateful for grant support from the Infectious Diseases Society of America through their Medical Scholars Program. We thank the Miami Center for AIDS Research (P30AI073961) for statistical support. Research reported in this publication was supported by the National Cancer Institute of the National Institutes of Health under Award Number P30CA240139. The content is solely the responsibility of the authors and does not necessarily represent the official views of the National Institutes of Health.

Authors' contributions: $\mathrm{KB}, \mathrm{AC}, \mathrm{AM}, \mathrm{HT}$, JSO all contributed to the design and interpretation of the study. $\mathrm{HL}$ and TB performed the statistical analysis. $\mathrm{KB}$ and $\mathrm{AC}$ were the major contributors writing the manuscript, aided by AM, TB, HT and JSO.

Acknowledgements: We would like to thank Drs. Susan Doblecki-Lewis, Maria Alcaide, and Jose Castro for their support of this work with feedback on project design, and Stephanie Moody-Geissler for support with epidemiological analysis.

\section{References}

1. Scholl L, Seth P, Kariisa M, Wilson N, Baldwin G. Drug and Opioid-Involved Overdose Deaths - United States, 2013-2017. MMWR Morb Mortal Wkly Rep. 2018;67(5152):1419-27.

2. Commission ME. Drug Identified In Deceased Persons by Florida Medical Examiners. Florida Department of Law Enforcement; 2017.

3. Centers for Disease Control and Prevention. HIV Surveillance Report, 2018 (Preliminary); vol. 30. http://www.cdc.gov/hiv/library/reports/hiv-surveillance.html. Published November 2019. Accessed [1/31/2020].

4. Mars SG, Ondocsin J, Ciccarone D. Toots, tastes and tester shots: user accounts of drug sampling methods for gauging heroin potency. Harm Reduct J. 2018;15(1):26.

5. Reed M, Wagner KD, Tran NK, Brady KA, Shinefeld J, Roth A. Prevalence and correlates of carrying naloxone among a community-based sample of opioid-using people who inject drugs. Int J Drug Policy. 2019;73:32-5.

6. Chimbar L, Moleta Y. Naloxone Effectiveness: A Systematic Review. J Addict Nurs. 2018;29(3):16771.

7. Wheeler E, Jones TS, Gilbert MK, Davidson PJ, Centers for Disease C, Prevention. Opioid Overdose Prevention Programs Providing Naloxone to Laypersons - United States, 2014. MMWR Morbidity and mortality weekly report. 2015;64(23):631-5. 
8. Bennett AS, Bell A, Doe-Simkins M, Elliott L, Pouget E, Davis C. From Peers to Lay Bystanders: Findings from a Decade of Naloxone Distribution in Pittsburgh, PA. J Psychoactive Drugs. 2018;50(3):240-6.

9. Giglio RE, Li G, DiMaggio CJ. Effectiveness of bystander naloxone administration and overdose education programs: a meta-analysis. Inj Epidemiol. 2015;2(1):10-.

10. McDonald R, Strang J. Are take-home naloxone programmes effective? Systematic review utilizing application of the Bradford Hill criteria. Addiction. 2016;111(7):1177-87.

11. Olsen A, McDonald D, Lenton S, Dietze PM. Assessing causality in drug policy analyses: How useful are the Bradford Hill criteria in analysing take-home naloxone programs? Drug Alcohol Rev. 2018;37(4):499-501.

12. Papp J, Vallabhaneni M, Morales A, Schrock JW. Take-home naloxone rescue kits following heroin overdose in the emergency department to prevent opioid overdose related repeat emergency department visits, hospitalization and death- a pilot study. BMC Health Serv Res. 2019;19(1):957.

13. Tookes H, Diaz C, Li H, Khalid R, Doblecki-Lewis S. A Cost Analysis of Hospitalizations for Infections Related to Injection Drug Use at a County Safety-Net Hospital in Miami, Florida. PLoS One. 2015;10(6):e0129360.

14. Alvarez L. Florida Shutting 'Pill Mill' Clinics. The New York Times. 2011.

15. Rutkow L, Chang H-Y, Daubresse M, Webster DW, Stuart EA, Alexander GC. Effect of Florida's Prescription Drug Monitoring Program and Pill Mill Laws on Opioid Prescribing and Use. JAMA Internal Medicine. 2015;175(10):1642-9.

16. Keane C, Egan JE, Hawk M. Effects of naloxone distribution to likely bystanders: Results of an agentbased model. Int J Drug Policy. 2018;55:61-9.

17. BCHD. Jurisdictional Plan for HIV Prevention in Baltimore City. Baltimore City; 2012. 2015.

\section{Supplementary Files}

\section{File name: Supplementary Table 1}

File Extension: JMH PWIO Data.sas7bdat

Title of data: JMH PWIO

Description of data: This data consists of the 302 admission of people who inject opioids that we analyzed in this manuscript.

\section{File name: Supplemental Table 2}

File Extension: JMH PWIO ICD-10 Codes.docx

Title of data: JMH PWIO ICD-10 Codes 
Description of data: This table contains the complete list of ICD-10 codes used for inclusion in the study as described in the Methods section.

\section{Figures}

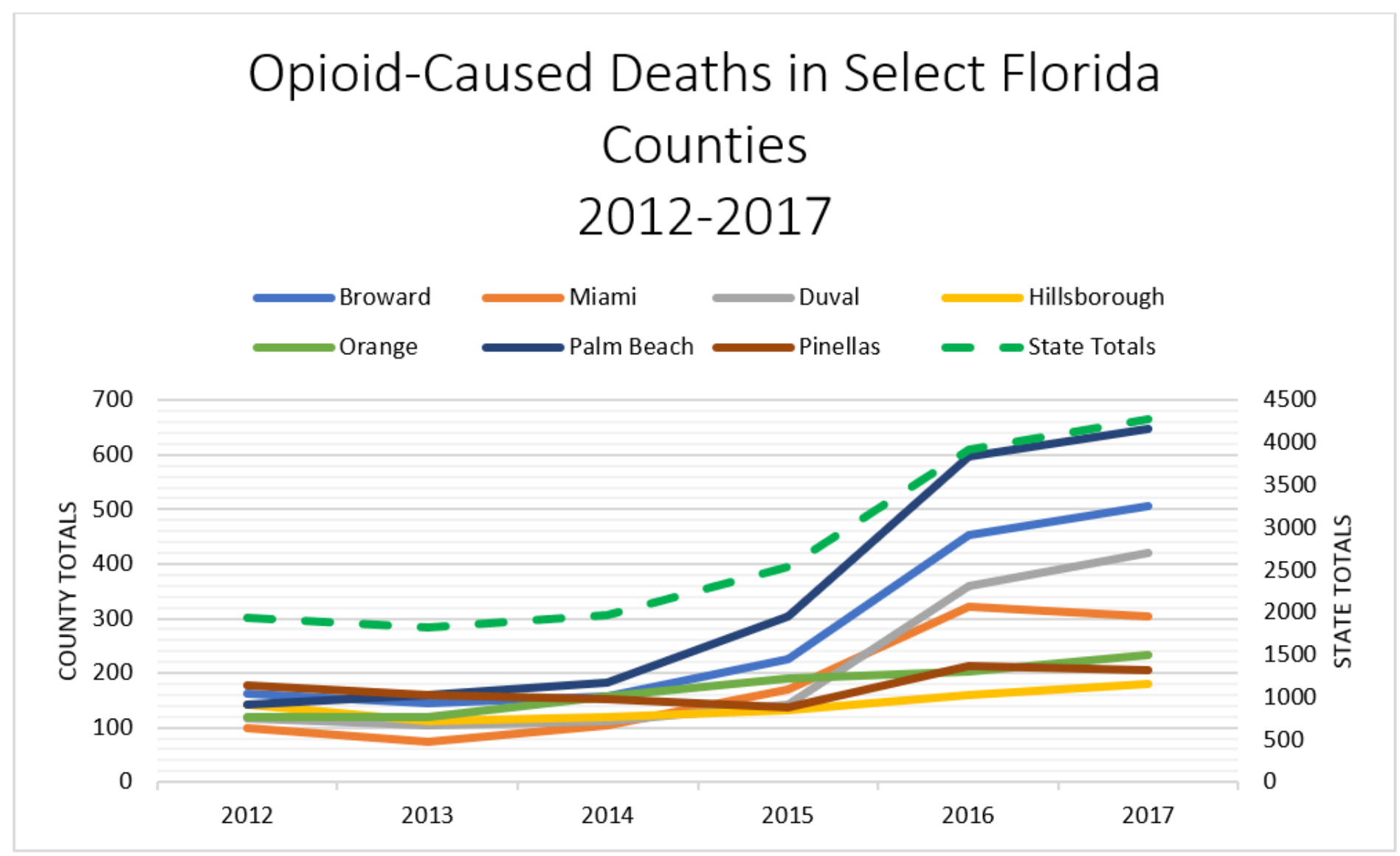

Figure 1

Opioid-Caused Deaths in Select Florida Counties 2012-2017

\section{Supplementary Files}

This is a list of supplementary files associated with this preprint. Click to download.

- JMHPWIOData.sas7bdat

- JMHPWIOICD10Codes.docx 